\title{
TRÍPTICO
}

\section{[RICHARD MAXWELL]}




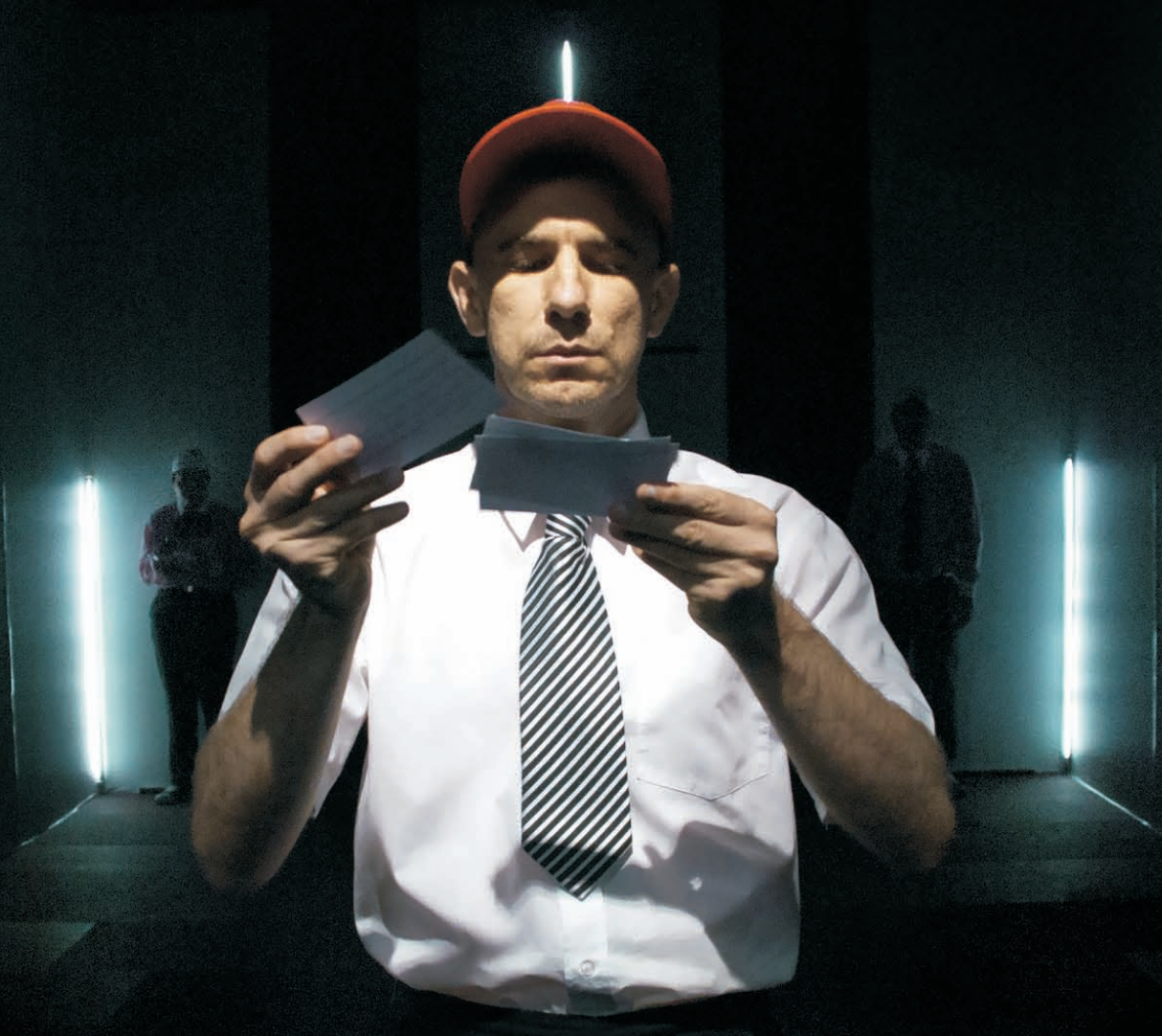

Ricardo Grasson acima, Anapaula Csernik, Janaina Afhonso, Kenan Bernardes, Renato Forner e Rodrigo Pavon em "Burger King" 2010 Fotografia Julieta Bacchin

BYRGER
KFNG

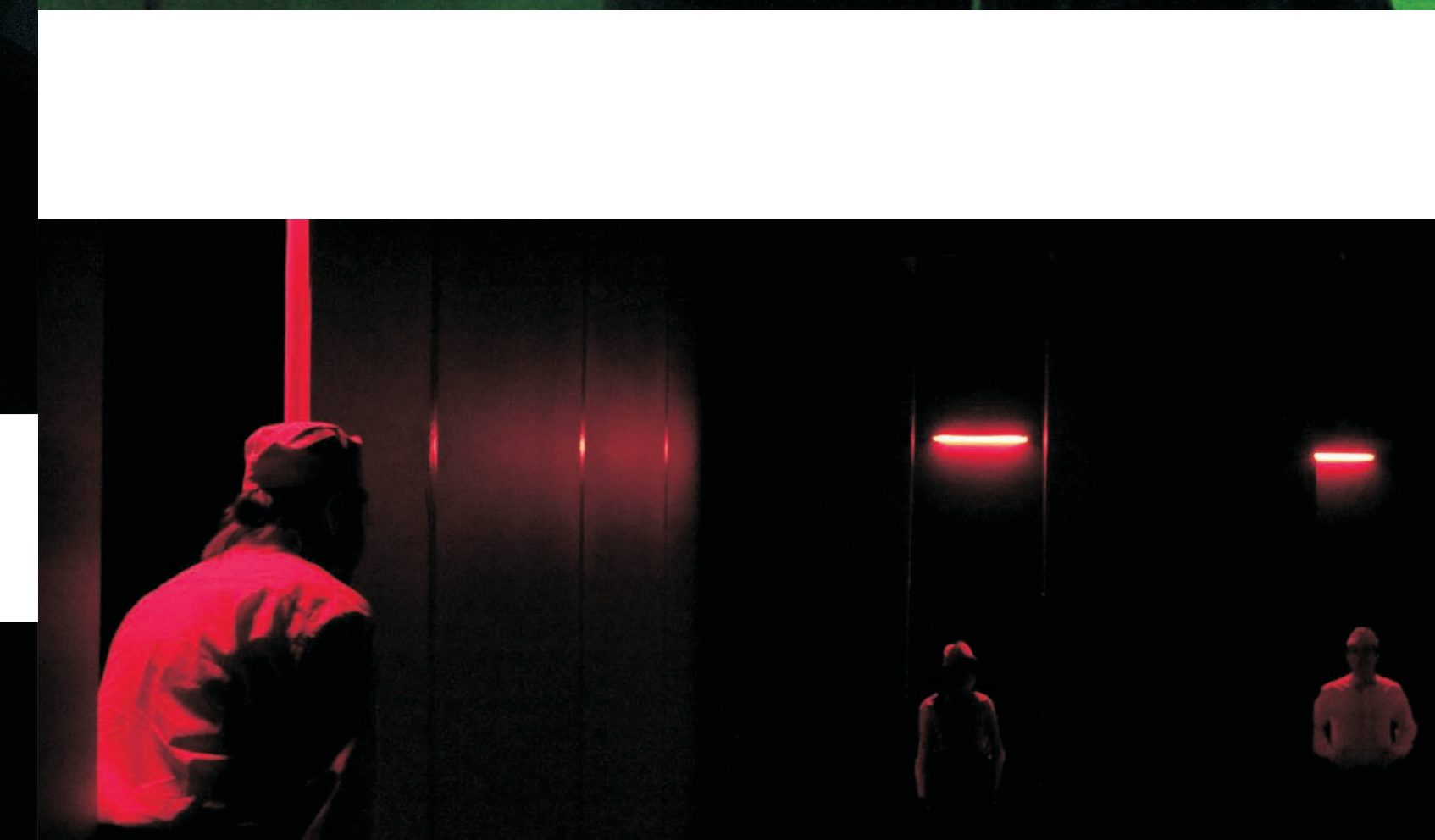

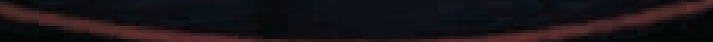




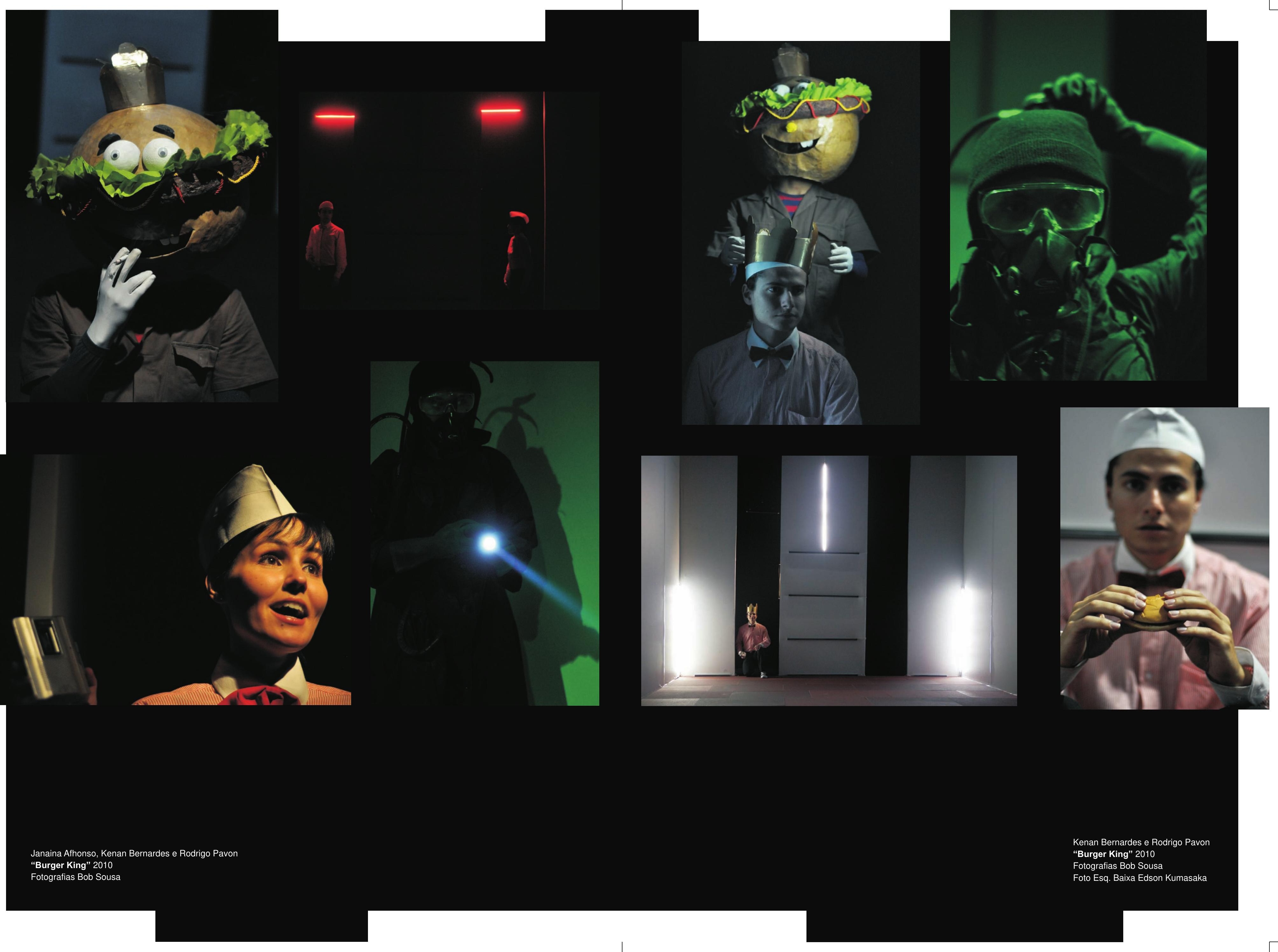



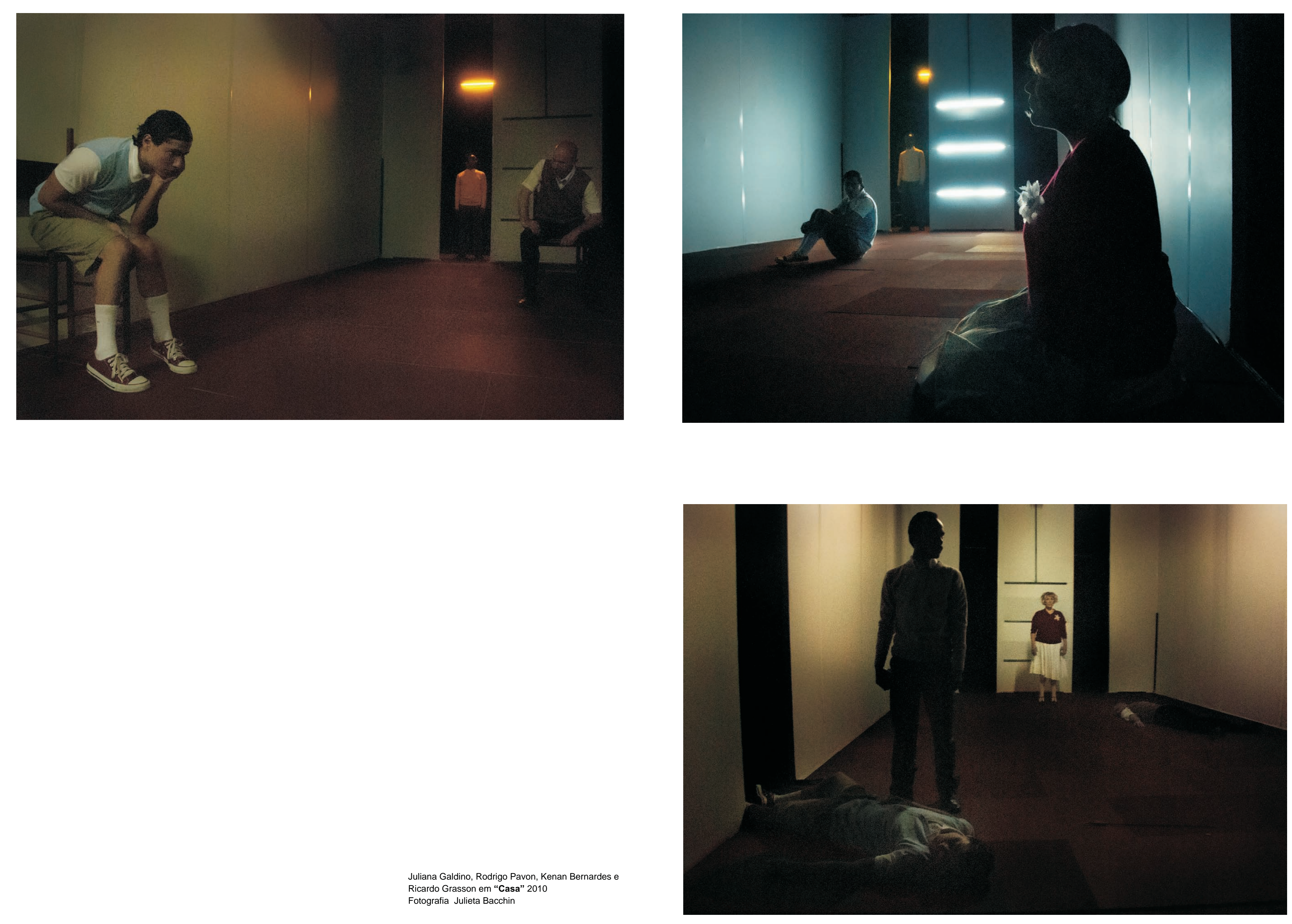



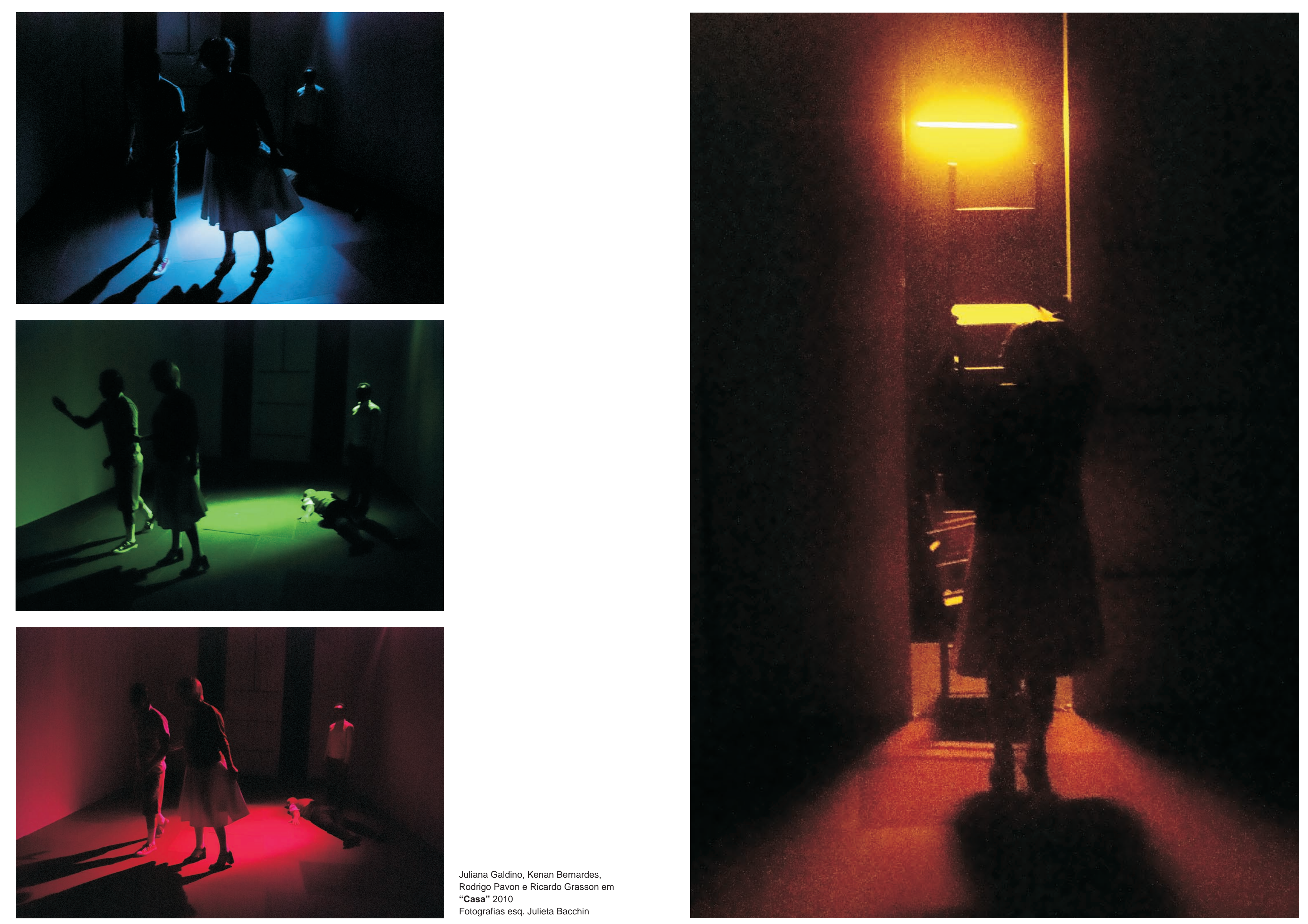

“Casa” 2010 Fotografias esq. Julieta Bacchin 

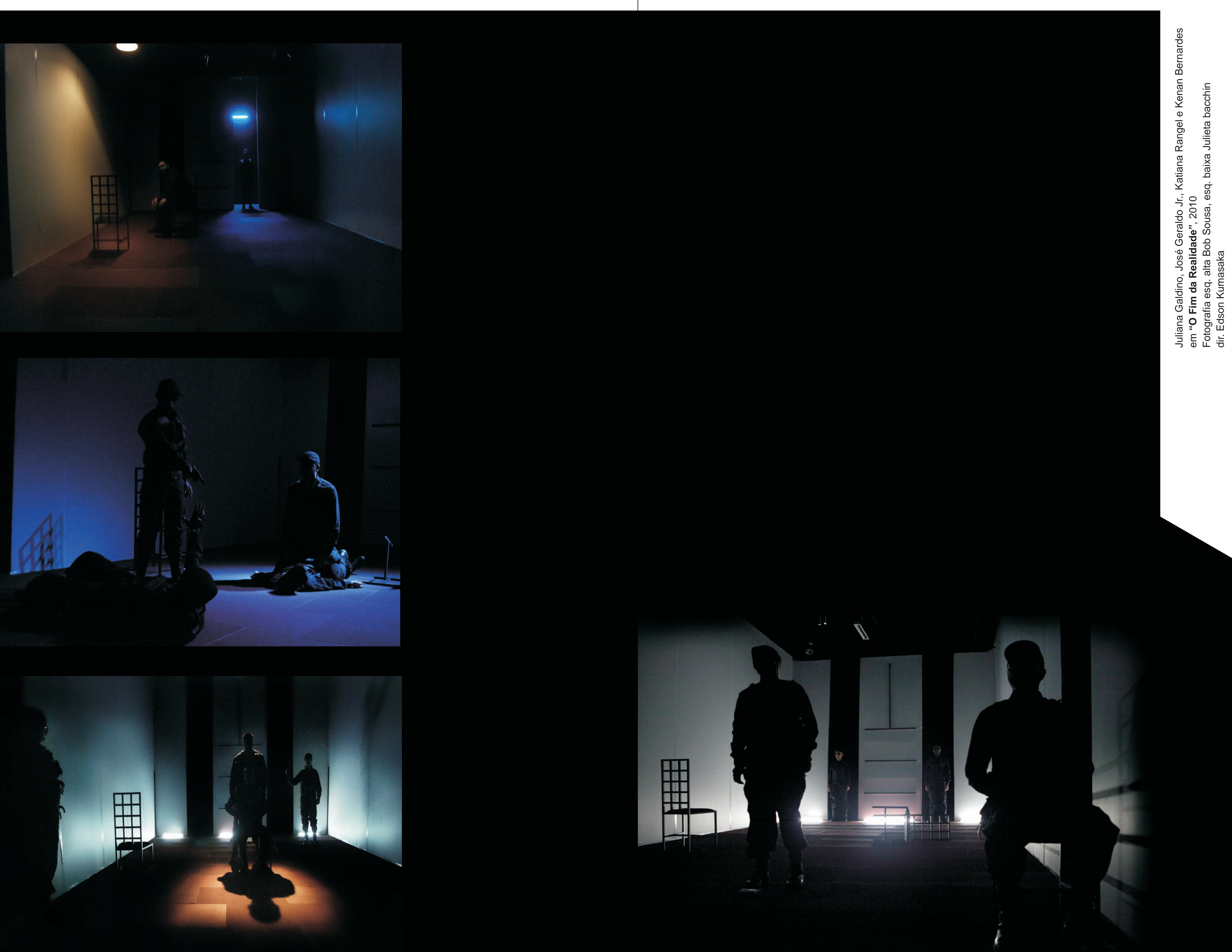

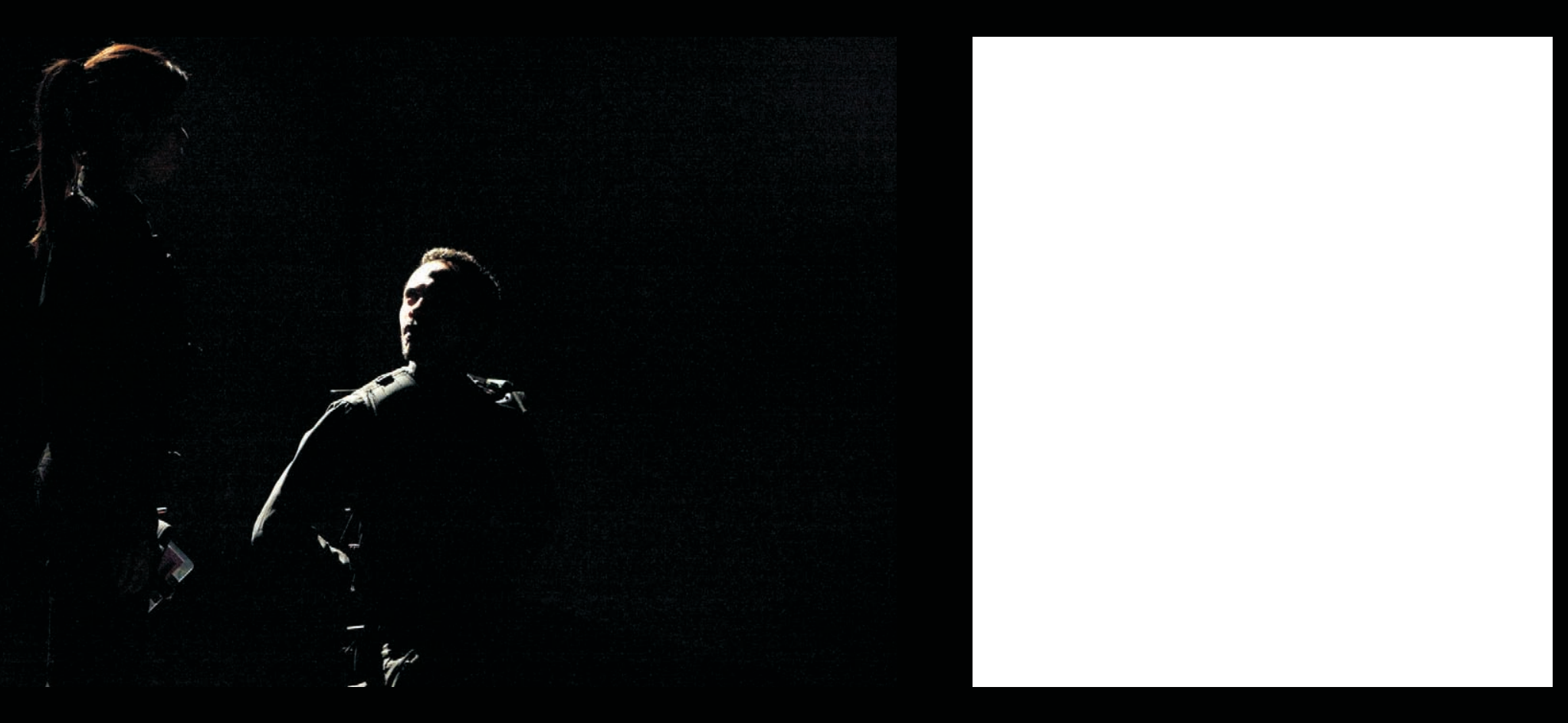

\{
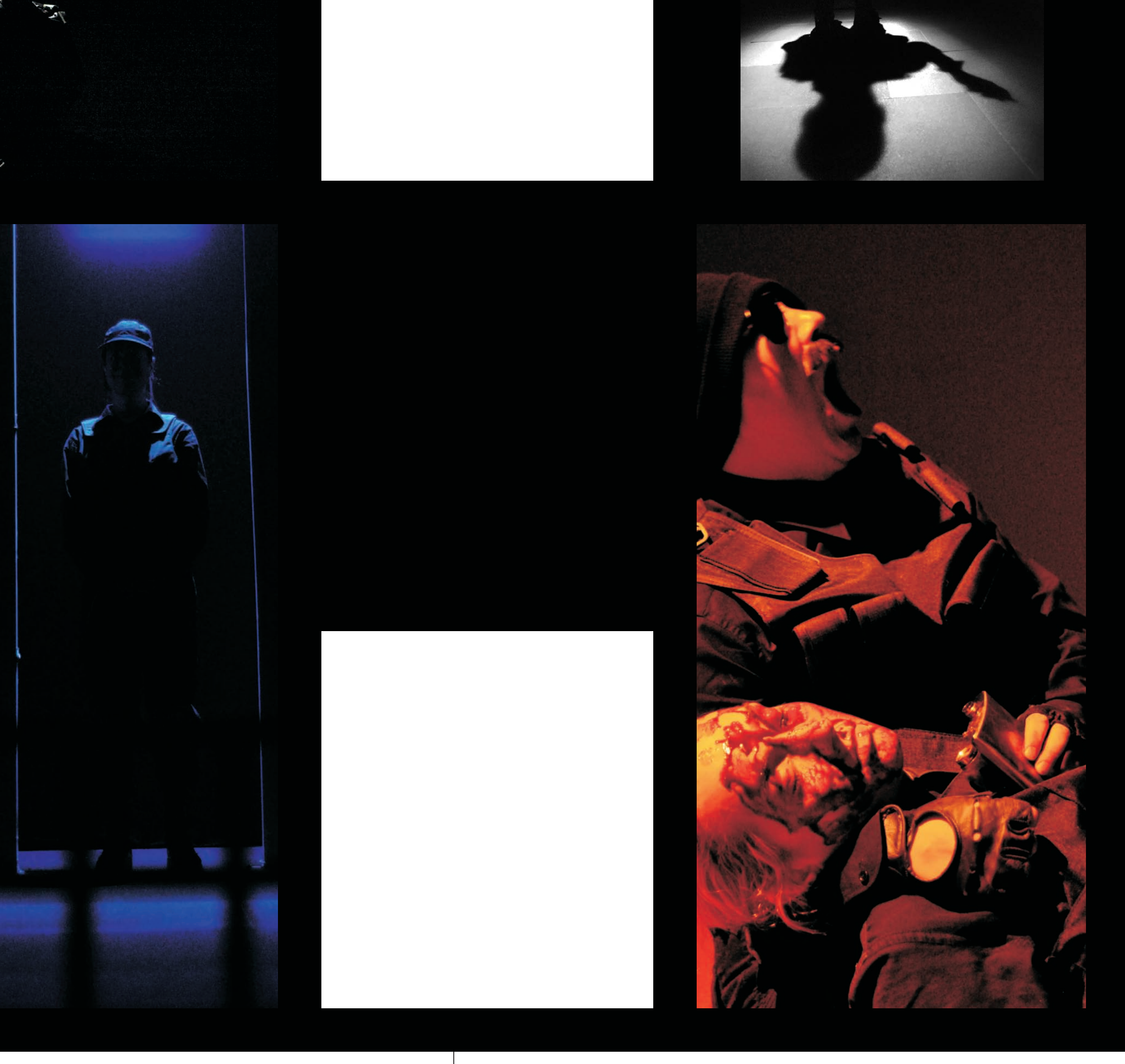
TRÍPTICO [RICHARD MAXWELL]

Burger King

Casa

O Fim da Realidade
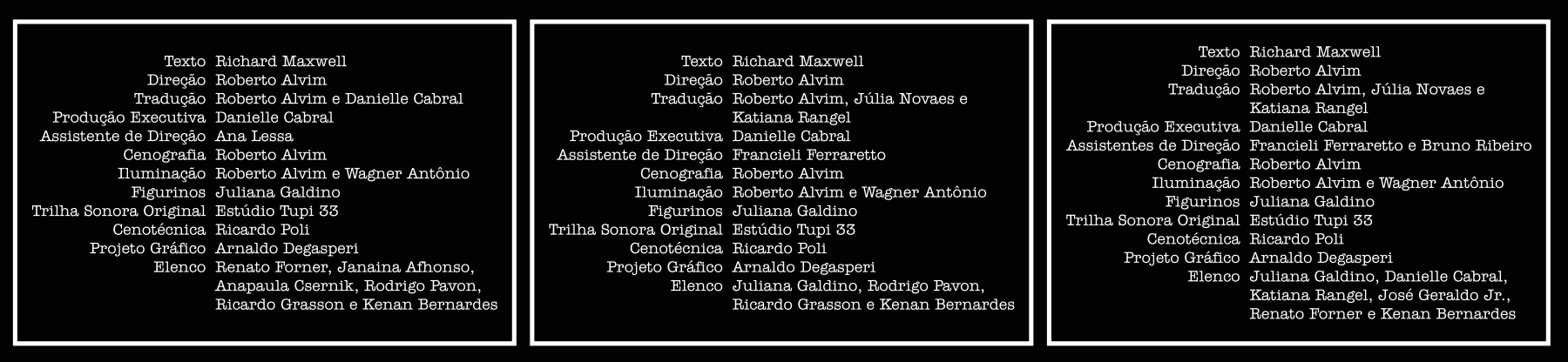

Projeto Gráfico Revista SALA PRETA Gê Viana

funarinte

www.ciaclubnoir.com.br 